\title{
A proteomic study of TAR-RNA binding protein (TRBP)-associated factors
}

\author{
Ya-Hui Chi ${ }^{1,3}$, Oliver John Semmes ${ }^{2}$, Kuan-Teh Jeang ${ }^{3 *}$
}

\begin{abstract}
Background: The human TAR RNA-binding protein, TRBP, was first identified and cloned based on its high affinity binding to the small hairpin trans-activation responsive (TAR) RNA of HIV-1. TRBP has more recently been found to be a constituent of the RNA-induced silencing complex (RISC) serving as a Dicer co-factor in the processing of the $\sim 70$ nucleotide pre-microRNAs(miRNAs) to 21-25 nucleotide mature miRNAs.
\end{abstract}

Findings: Using co-immunoprecipitation and protein-identification by mass spectrometry, we characterized intracellular proteins that complex with TRBP. These interacting proteins include those that have been described to act in protein synthesis, RNA modifications and processing, DNA transcription, and cell proliferation.

Conclusions: Our findings provide a proteome of factors that may cooperate with TRBP in activities such as miRNA processing and in RNA interference by the RISC complex.

\section{Findings}

MicroRNAs (miRNAs) are important regulators of cellular development, differentiation, proliferation, apoptosis, metabolism, and oncogenesis [1-4]. Cellular miRNAs have also been proposed to function in restricting virus infection of cells [5-11]. The biogenesis of miRNAs in eukaryotic cells has been reviewed extensively elsewhere $[12,13]$. In brief, RNA polymerase II transcribed primary microRNA transcripts (pri-miRNA) are processed by Drosha in the nucleus to pre-miRNA precursors which are then processed by Dicer in the cytoplasm to mature miRNAs. In analyzing miRNA processing, it was noted that a cellular protein, TAR RNA-binding protein TRBP, binds directly to Dicer [14-17] and is important to the activity of miRNA-mediated RNA-silencing. Moreover, a TRBP-Ago2 composed RNA-induced silencing complex (RISC) has been shown to be needed for optimal miRNA-guided post-transcriptional silencing [18].

TRBP contains two double-stranded RNA binding domains (RBD) [17] and was originally characterized and cloned based on its high affinity binding to the HIV-1 small hairpin leader RNA, TAR [19-21].

\footnotetext{
* Correspondence: kjeang@niaid.nih.gov

${ }^{3}$ Molecular Virology Section, Laboratory of Molecular Microbiology, National Institute of Allergy and Infectious Diseases, National Institutes of Health, Bethesda, MD, USA

Full list of author information is available at the end of the article
}

Consistent with the notion of miRNA-mediated restriction of viral infection in mammalian cells, loss of TRBP activity through its sequestration by TAR RNA resulted in the enhanced replication of HIV-1 in human cells [22]. To date, TRBP is considered to act inside cells through at least three different mechanisms: it can promote the translation of TAR RNA-containing viral RNAs [23]; it can directly bind and inhibit the interferon (IFN)-induced double-stranded RNA (dsRNA)-activated protein kinase R (PKR) [24]; and as mentioned above, it can be a Dicer co-factor in the miRNA/siRNA RNAi pathway. To gain additional insight into TRBP function, we sought to identify human cellular factors that associate with TRBP. Here, using co-immunoprecipitation (co-IP) and protein-identification by mass spectrometry, we report proteins in a TRBP-proteome.

Figure 1A shows the Coomassie blue stained profile of proteins that co-IP with TRBP. After treating with RNase A, the majority (> 80\%) of the co-IP products were reduced in amounts, suggesting that many TRBP-interacting partners in the co-IP are indirectly linked via RNA-association (silver stain, Figure 1B). Next, we compared "Mock" to "TRBP" samples based on silver staining; and we excised the corresponding Coomassie blue stained protein bands that were enhanced in the TRBP sample. These bands were then analyzed by LC-MS/MS spectrometry (Figure 1A). The corresponding gel bands from the "Mock" sample 


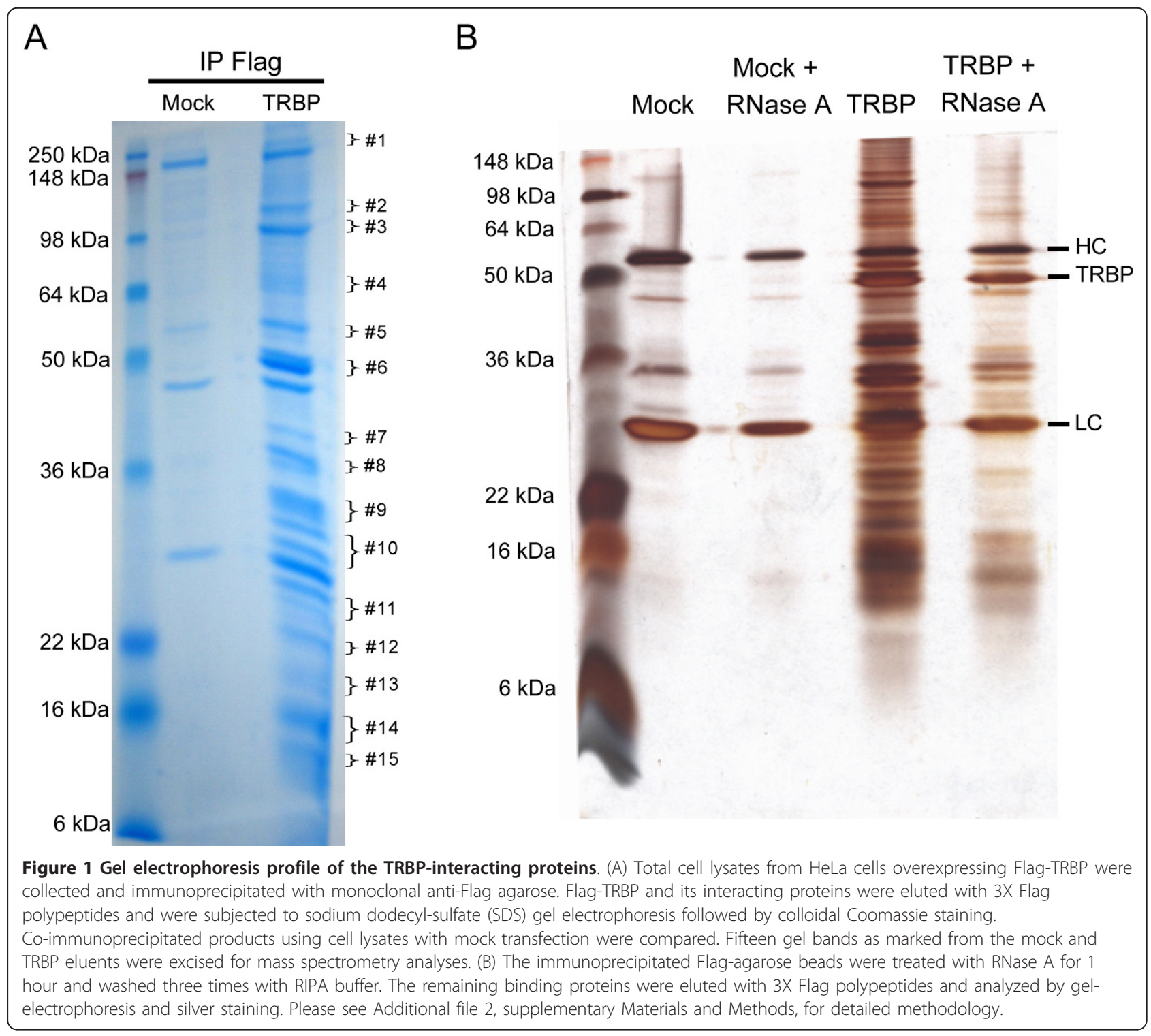

were also excised and analyzed in parallel. By subtracting the "Mock" protein identification data from the "TRBP" protein identification data, 160 "TRBP-associated" factors were identified (Additional file 1, Table S1). The functional relevance (according to the $\mathrm{p}$ value computed by the Ingenuity Systems algorithm using right-tailed Fisher Exact Test) of each category of protein factors to established pathways is diagrammed in Figure 2, and the protein identities present in each functional category are listed in Table 1. Similar to a previous report [25], our results show that TRBP is significantly associated with factors in the protein synthesis machinery that is constituted by the $80 \mathrm{~S}$ ribosome [ 20 out of 32 proteins (RPSs; ribosomal protein, small subunits) of the $40 \mathrm{~S}$ ribosomal subunits, and 24 out of 46 proteins (RPLs; ribosomal protein, large subunits) of the $60 \mathrm{~S}$ ribosomal subunit were identified] [26]. Also identified were several translation elongation factors (e.g. ABCF1, EEF1A2, EIF2AK2 and EIF2S1) (Table 1).

Although previous reports implicated TRBP as active primarily in the cytoplasm, our mass spectrometry results (Additional file 2. Supplementary Materials and Methods) identified several TRBP-interacting nuclear factors which are known to participate in processes including RNA splicing, cellular growth and proliferation and gene transcription (Figure 2, Table 1; and Additional file 1, Table S1). For example, EFTUD2, HNRPC, PRPF8, PTBP1, SFRS1, SYNCRIP, SNRPD1, SNRPD3 and U2AF1 are components of the small nuclear ribonucleoprotein (snRNPs) that are involved in splicing of pre-mRNAs. Related to gene transcription, TRBP-associated proteins include those found 


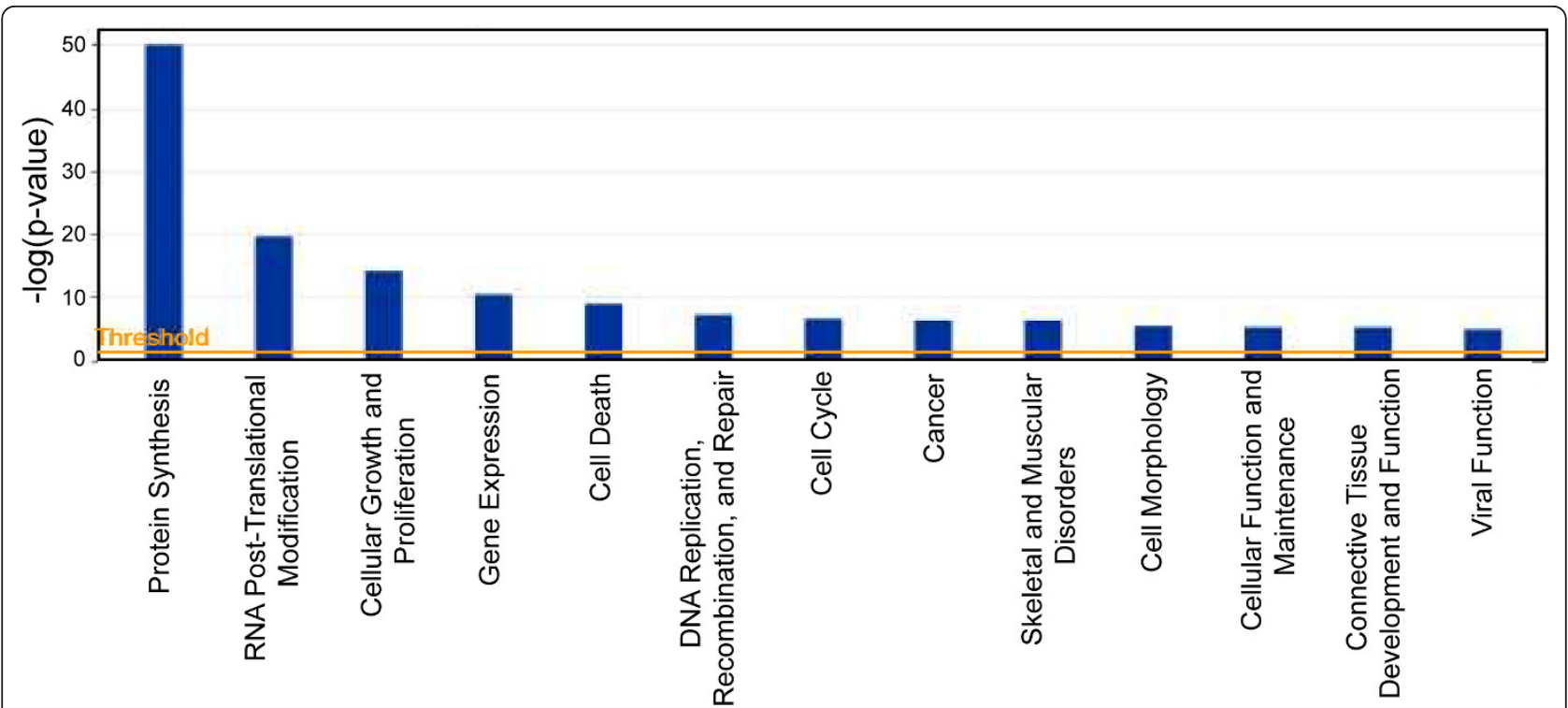

Figure 2 Functional categorization of the TRBP-interacting proteins. Categorization of the molecular function of the 160 TRBP interacting proteins was done using the Ingenuity Pathway Analysis software. The $y$-axis shows statistical relevance of the TRBP-interacting factors in the indicated functional categories. The protein identities of TRBP-associated factors in each functional category are summarized in Table 1.

to be active in RNA polymerase II- and III-dependent transcription (Additional file 1, Table S1). Additionally, a TRBP-associated factor, Sox21, is a HMG-box transcription factor that acts in a complex array of repressive and activating transcriptional processes in embryonic stem cells [27]. The transcription co-activator HMGA1 was also identified in our proteomic data (Table 1). Whether TRBP participates in the determination of pluripotency through Sox21 requires further study.

Recently, TRBP truncating mutations were found in human cancers with microsatellite instability [28]. Evidence exists which supports the notion that impaired

Table 1 Functional categories of the TRBP-associated complex

\begin{tabular}{ll}
\hline Category & Molecules \\
\hline Protein Synthesis & ABCF1, EEF1A2, EIF2AK2, EIF2S1, PTBP1, RPL3, RPL4, RPL5, RPL6, RPL7, RPL9, RPL11, RPL15, \\
& RPL18, RPL21, RPL22, RPL24, RPL30, RPL32, RPL34, RPL35, RPL18A, RPL23A, RPL27A, RPL29 \\
& (includes EG:6159), RPL31 (includes EG:6160), RPL7A (includes EG:6130), RPS2, RPS5, RPS6, RPS9, \\
& RPS10, RPS11, RPS17 (includes EG:6218), RPS3A \\
& DDX17, DDX54, EFTUD2, HNRPAB, HNRPC, HNRPUL1, PABPC1, PRPF8, PTBP1, SFRS1, SNRPD1, \\
RNA Post-Transcriptional Modification & SNRPD3, SYNCRIP, U2AF1 \\
& AKAP13, ATP5B, ATP5F1, CCT2, DBN1, DCD, DNAJA3, EIF2AK2, GLTSCR2, HMGA1, HNRPA1, \\
Cellular Growth and Proliferation & HNRPAB, HNRPC, HNRPF, HNRPM, PHB (includes EG:5245), PPP1R9B, PRPF8, PRPF19, RAP1B, \\
& RPS3A, RSL1D1, SART1, SFRS1, TOP1, XRN2 \\
& BASP1, BTF3, CDC5L, CHD4, CSDA, DDX5, DEK, EIF2S1, GTF3C1, GTF3C3, GTF3C4, HMGA1, \\
Gene Expression & HNRPAB, IGHMBP2, PARP1, PHB (includes EG:5245), RBM39, RPL6, SOX21, TARBP2, TOP1, TOP2A \\
& DDX5, DIDO1, DNAJA3, EEF1A2, EIF2AK2, EIF2S1, GNL3, HIST1H1C, HMGA1, HNRPA1, HNRPC, \\
Cell Death & HSPA1B, PARP1, PHB (includes EG:5245), PPP1R9B, PRPF19, RBBP4, RPLP0 (includes EG:6175), \\
& RPS3A, SLC2A1, TOP1, TOP2A \\
DNA Replication, Recombination, and Repair & CDC5L, HMGA1, HSPA1B, IGHMBP2, PARP1, PRPF19, TOP1, TOP2A \\
Cell Cycle & CDC5L, EIF2AK2, GNL3, HMGA1, NOL1, PARP1, PES1, PHB (includes EG:5245), PPP1R9B, PRMT5, \\
& RPL5, RPL11, RPL23, TOP2A \\
Cancer & RPL5, RPL11, RPL23, AKAP13, ASPH, DNAJA3, HMGA1, HSPA1B, PES1, PRMT5, RPS3A \\
Skeletal and Muscular Disorders & RPL5, RPL11, RPL23 \\
Cell Morphology & AKAP13, ASPH, DNAJA3, HMGA1, HSPA1B, PES1, PRMT5, RPS3A \\
Cellular Function and Maintenance/Connective & EIF2AK2, EIF2S1 \\
Tissue Development and Function & \\
Viral Function & AKAP13, EIF2AK2, HMGA1, PARP1, SFRS1 \\
\hline
\end{tabular}


miRNA processing and destabilization of the DICER1 protein are correlated with tumorigenesis [28]. Because TRBP is known to interact with Dicer and to be involved in mRNA processing, how TRBP and TRBPinteracting proteins contribute to oncogenesis merits future investigation. The current TRBP proteome provides a starting point for initiating those explorations. Our study describes the TRBP-proteome in HeLa cells. Although TRBP was originally identified as the HIV-1 TAR RNA-binding protein, its more recently characterized function in microRNA biogenesis and RISC-activity is widely conserved in all cell types (e.g. epithelial, hematopoietic, mesenchymal cells etc...). Thus, a HeLalike TRBP-proteome is likely to be found in all types of human cells. We realize that systematic functional validation of the currently identified TRBP proteome will be necessary in order to clarify the biological relevance of each factor. Indeed, some of the TRBP-interacting proteins are being currently characterized.

\section{Additional material}

Additional file 1: Supplementary Table S1. Pubmed ID, gene name, functional description, hits in proteomics study and alternative symbol for TRBP-interacting factors.

Additional file 2: Supplementary Materials and Methods

\section{Abbreviations}

TRBP: TAR-RNA binding protein 2; RISC: RNA-induced silencing complex; TAR: trans-activation responsive element.

\section{Acknowledgements}

Work in the KTJ laboratory was supported in part by NIAID/NIH intramural funds and by the Intramural AIDS Targeted Anti-viral Program (IATAP).

\section{Author details}

'Institute of Cellular and System Medicine, National Health Research Institutes, Zhunan, Taiwan. ${ }^{2}$ Department of Microbiology and Molecular Cell Biology, The Leroy T. Canoles Jr. Cancer Research Center "Eastern Virginia Medical School, Norfolk, Virginia, USA. ${ }^{3}$ Molecular Virology Section, Laboratory of Molecular Microbiology, National Institute of Allergy and Infectious Diseases, National Institutes of Health, Bethesda, MD, USA.

\section{Authors' contributions}

YHC constructed the TRBP expression plasmid, performed coimmunoprecipitations, prepared MS samples, analyzed the results; OJS provided mass spectrometry analyses; KTJ conceived of the study. YHC and KTJ prepared the manuscript. All authors read and approved the final manuscript.

\section{Competing interests}

The authors declare that they have no competing interests.

Received: 27 January 2011 Accepted: 25 February 2011 Published: 25 February 2011

\section{References}

1. Garzon R, Fabbri M, Cimmino A, Calin GA, Croce CM: MicroRNA expression and function in cancer. Trends Mol Med 2006, 12:580-587.

2. Svoboda P, Flemr M: The role of miRNAs and endogenous siRNAs in maternal-to-zygotic reprogramming and the establishment of pluripotency. EMBO Rep 2010, 11:590-597.
3. Lewis MA, Steel KP: MicroRNAs in mouse development and disease. Semin Cell Dev Biol 2010, 21:774-780.

4. Yeung ML, Bennasser $Y$, Jeang $K T$ : miRNAs in the biology of cancers and viral infections. Curr Med Chem 2007, 14:191-197.

5. Berkhout B, Jeang KT: RISCy business: MicroRNAs, pathogenesis, and viruses. J Biol Chem 2007, 282:26641-26645.

6. Watanabe Y, Kishi A, Yachie N, Kanai A, Tomita M: Computational analysis of microRNA-mediated antiviral defense in humans. FEBS Lett 2007, 581:4603-4610.

7. Yeung ML, Benkirane M, Jeang KT: Small non-coding RNAs, mammalian cells, and viruses: regulatory interactions? Retrovirology 2007, 4:74.

8. Grassmann $\mathrm{R}$, Jeang $\mathrm{KT}$ : The roles of microRNAs in mammalian virus infection. Biochim Biophys Acta 2008, 1779:706-711.

9. Triboulet R, Mari B, Lin YL, Chable-Bessia C, Bennasser Y, Lebrigand K, et at: Suppression of microRNA-silencing pathway by HIV-1 during virus replication. Science 2007, 315:1579-1582.

10. Chable-Bessia C, Meziane O, Latreille D, Triboulet R, Zamborlini A, Wagschal A, et al: Suppression of HIV-1 replication by microRNA effectors. Retrovirology 2009, 6:26.

11. Strebel $\mathrm{K}$, Luban J, Jeang $\mathrm{KT}$ : Human cellular restriction factors that target HIV-1 replication. BMC Med 2009, 7:48.

12. Jaskiewicz $\mathrm{L}$, Filipowicz W: Role of Dicer in posttranscriptional RNA silencing. Curr Top Microbiol Immunol 2008, 320:77-97.

13. Ambros V: The functions of animal microRNAs. Nature 2004, 431:350-355.

14. Haase AD, Jaskiewicz L, Zhang H, Laine S, Sack R, Gatignol A, et al: TRBP, a regulator of cellular PKR and HIV-1 virus expression, interacts with Dicer and functions in RNA silencing. EMBO Rep 2005, 6:961-967.

15. Chendrimada TP, Gregory RI, Kumaraswamy E, Norman J, Cooch N, Nishikura K, et al: TRBP recruits the Dicer complex to Ago2 for microRNA processing and gene silencing. Nature 2005, 436:740-744.

16. Kok KH, Ng MH, Ching YP, Jin DY: Human TRBP and PACT directly interact with each other and associate with dicer to facilitate the production of small interfering RNA. J Biol Chem 2007, 282:17649-17657.

17. Daniels SM, Melendez-Pena CE, Scarborough RJ, Daher A, Christensen HS, El FM, et al: Characterization of the TRBP domain required for dicer interaction and function in RNA interference. BMC Mol Biol 2009, 10:38.

18. Watashi $\mathrm{K}$, Yeung ML, Starost MF, Hosmane RS, Jeang KT: Identification of small molecules that suppress microRNA function and reverse tumorigenesis. J Biol Chem 2010, 285:24707-24716.

19. Gatignol A, Buckler-White A, Berkhout B, Jeang KT: Characterization of a human TAR RNA-binding protein that activates the HIV-1 LTR. Science 1991, 251:1597-1600

20. Gatignol A, Buckler C, Jeang KT: Relatedness of an RNA-binding motif in human immunodeficiency virus type 1 TAR RNA-binding protein TRBP to human P1/dsl kinase and Drosophila staufen. Mol Cell Biol 1993, 13:2193-2202.

21. Duarte M, Graham K, Daher A, Battisti PL, Bannwarth S, Segeral E, et al: Characterization of TRBP1 and TRBP2. Stable stem-loop structure at the $5^{\prime}$ end of TRBP2 mRNA resembles HIV-1 TAR and is not found in its processed pseudogene. J Biomed Sci 2000, 7:494-506.

22. Bennasser $Y$, Yeung ML, Jeang KT: HIV-1 TAR RNA subverts RNA interference in transfected cells through sequestration of TAR RNAbinding protein, TRBP. J Biol Chem 2006, 281:27674-27678.

23. Dorin D, Bonnet MC, Bannwarth S, Gatignol A, Meurs EF, Vaquero C: The TAR RNA-binding protein, TRBP, stimulates the expression of TARcontaining RNAs in vitro and in vivo independently of its ability to inhibit the dsRNA-dependent kinase PKR. J Biol Chem 2003, 278:4440-4448

24. Benkirane M, Neuveut C, Chun RF, Smith SM, Samuel CE, Gatignol A, et al: Oncogenic potential of TAR RNA binding protein TRBP and its regulatory interaction with RNA-dependent protein kinase PKR. EMBO 1997, 16:611-624.

25. Chendrimada TP, Finn K, Ji X, Baillat D, Gregory Rl, Liebhaber SA, et al: MicroRNA silencing through RISC recruitment of elF6. Nature 2007, 447:823-828

26. Wilson DN, Nierhaus KH: Ribosomal proteins in the spotlight. Crit Rev Biochem Mol Biol 2005, 40:243-267.

27. Chakravarthy H, Ormsbee BD, Mallanna SK, Rizzino A: Rapid activation of the bivalent gene Sox21 requires displacement of multiple layers of gene-silencing machinery. FASEB J 2011, 25:206-218. 
28. Melo SA, Ropero S, Moutinho C, Aaltonen LA, Yamamoto H, Calin GA, et al: A TARBP2 mutation in human cancer impairs microRNA processing and DICER1 function. Nat Genet 2009, 41:365-370.

doi:10.1186/2045-3701-1-9

Cite this article as: Chi et al:: A proteomic study of TAR-RNA binding protein (TRBP)-associated factors. Cell \& Bioscience 2011 1:9.

Submit your next manuscript to BioMed Central and take full advantage of:

- Convenient online submission

- Thorough peer review

- No space constraints or color figure charges

- Immediate publication on acceptance

- Inclusion in PubMed, CAS, Scopus and Google Scholar

- Research which is freely available for redistribution

Submit your manuscript at www.biomedcentral.com/submit 